Short Communication

\title{
Microstructure and Corrosion Resistance of Zn-Al-Mg Alloy Diffusion Coating developed on Carbon Steel by Hot Dipping
}

Zhenyue Zhang*, Zengwu Yue, Xingeng Li, Bo Jiang, Feifei Wang ,Zhibin Fan ,Fengjie Yan, Wenjing Li, Yaping Wu, Chunxu Mi, Zhiyue Gao

State Grid Shandong Electric Power Research Institute, Jinan 250000, China

*E-mail: zhangzhenyue@sina.cn

doi: $10.20964 / 2020.06 .62$

Received: 16 January 2020 / Accepted: 30 March 2020 / Published: 10 May 2020

Carbon steel samples were galvanized in $\mathrm{Zn}-6 \% \mathrm{Al}-3 \% \mathrm{Mg}$ alloy at $455^{\circ} \mathrm{C}$ and $475^{\circ} \mathrm{C}$, respectively. Two kinds of coatings with different microstructure were obtained. The samples were examined with SEM, EDX, XRD, electrochemical and neutral salt spray test. The results show that these two coatings obtained in this study were all diffusion coatings, Al rich phase was mainly Fe2Al5Znx, and no Al phase was detected. The formation mechanism of these coatings were discussed.

Keywords: galvanizing;corrosion; diffusion; intermetallic;polarization test

\section{FULL TEXT}

(C) 2020 The Authors. Published by ESG (www.electrochemsci.org). This article is an open access article distributed under the terms and conditions of the Creative Commons Attribution license (http://creativecommons.org/licenses/by/4.0/). 